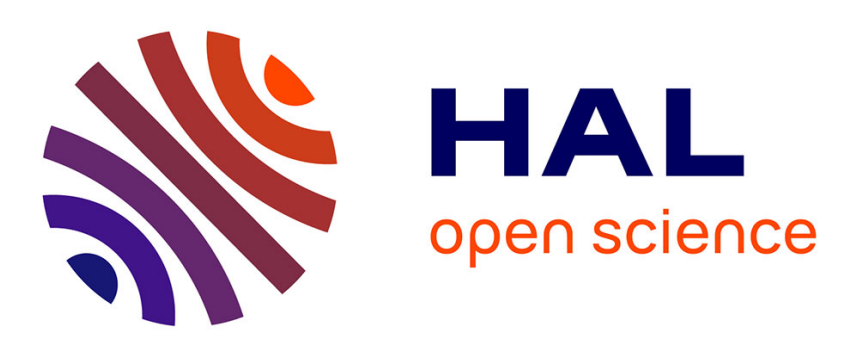

\title{
Inhibitory modulation of the mitochondrial permeability transition by minocycline
}

Anne Gieseler, Adrian Tilman Schultze, Kathleen Kupsch, Mohammad Fahad Haroon, Gerald Wolf, Detlef Siemen, Peter Kreutzmann

\section{> To cite this version:}

Anne Gieseler, Adrian Tilman Schultze, Kathleen Kupsch, Mohammad Fahad Haroon, Gerald Wolf, et al.. Inhibitory modulation of the mitochondrial permeability transition by minocycline. Biochemical Pharmacology, 2009, 77 (5), pp.888. 10.1016/j.bcp.2008.11.003 . hal-00531839

\section{HAL Id: hal-00531839 \\ https://hal.science/hal-00531839}

Submitted on 4 Nov 2010

HAL is a multi-disciplinary open access archive for the deposit and dissemination of scientific research documents, whether they are published or not. The documents may come from teaching and research institutions in France or abroad, or from public or private research centers.
L'archive ouverte pluridisciplinaire HAL, est destinée au dépôt et à la diffusion de documents scientifiques de niveau recherche, publiés ou non, émanant des établissements d'enseignement et de recherche français ou étrangers, des laboratoires publics ou privés. 


\section{Accepted Manuscript}

Title: Inhibitory modulation of the mitochondrial permeability transition by minocycline

Authors: Anne Gieseler, Adrian Tilman Schultze, Kathleen

Kupsch, Mohammad Fahad Haroon, Gerald Wolf, Detlef

Siemen, Peter Kreutzmann

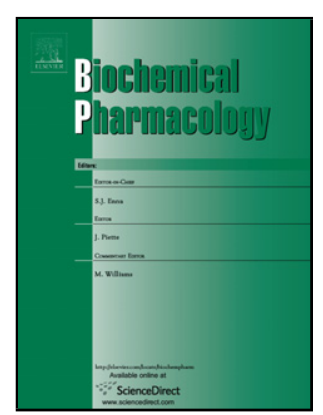

PII:

S0006-2952(08)00788-0

DOI: doi:10.1016/j.bcp.2008.11.003

Reference: BCP 10003

To appear in: $\quad B C P$

Received date: $\quad 30-9-2008$

Revised date: 3-11-2008

Accepted date: $\quad 3-11-2008$

Please cite this article as: Gieseler A, Schultze AT, Kupsch K, Haroon MF, Wolf G, Siemen D, Kreutzmann P, Inhibitory modulation of the mitochondrial permeability transition by minocycline, Biochemical Pharmacology (2008), doi:10.1016/j.bcp.2008.11.003

This is a PDF file of an unedited manuscript that has been accepted for publication. As a service to our customers we are providing this early version of the manuscript. The manuscript will undergo copyediting, typesetting, and review of the resulting proof before it is published in its final form. Please note that during the production process errors may be discovered which could affect the content, and all legal disclaimers that apply to the journal pertain. 


\section{Inhibitory modulation of the mitochondrial permeability}

\section{transition by minocycline}

Anne Gieseler ${ }^{\mathrm{a}, 1}$, Adrian Tilman Schultze ${ }^{\mathrm{b}, 1}$, Kathleen Kupsch ${ }^{\mathrm{a}}$, Mohammad Fahad Haroon ${ }^{a}$, Gerald Wolf ${ }^{a}$, Detlef Siemen ${ }^{b}$, Peter Kreutzmann ${ }^{a}$,

a Institute of Medical Neurobiology, Otto-von-Guericke University Magdeburg, Leipziger Str. 44, D-39120 Magdeburg, Germany

b Department of Neurology, Otto-von-Guericke University Magdeburg, Leipziger Str. 44, D-39120 Magdeburg, Germany

1 These authors contributed equally to this work.

* Corresponding author:

Peter Kreutzmann, Ph.D.

Institute of Medical Neurobiology

Otto-von-Guericke University Magdeburg

Leipziger Str. 44

D-39120 Magdeburg

Germany

Phone: +49-(0)391-6714361

Fax: $\quad+49-(0) 391-6714365$

E-mail: peter.kreutzmann@med.ovgu.de 


\author{
Abstract \\ The semisynthetic tetracycline derivative minocycline exerts neuroprotective \\ properties in various animal models of neurodegenerative disorders. Although anti- \\ inflammatory and anti-apoptotic effects are reported to contribute to the \\ neuroprotective action, the exact molecular mechanisms underlying the beneficial \\ properties of minocycline remain to be clarified. We analyzed the effects of \\ minocycline in a cell culture model of neuronal damage and in single-channel \\ measurements on isolated mitoplasts. Treatment of neuron-enriched cortical cultures \\ with rotenone, a high affinity inhibitor of the mitochondrial complex I, resulted in a \\ deregulation of the intracellular $\mathrm{Ca}^{2+}$ dynamics, as recorded by live cell imaging. \\ Minocycline $(100 \mu \mathrm{M})$ and cyclosporin $\mathrm{A}(2 \mu \mathrm{M})$, a known inhibitor of the \\ mitochondrial permeability transition pore, decreased the rotenone-induced $\mathrm{Ca}^{2+}$ \\ deregulation by $60.9 \%$ and $37.6 \%$, respectively. Investigations of the mitochondrial \\ permeability transition pore by patch-clamp techniques revealed for the first time a \\ dose-dependent reduction of the open probability by minocycline $\left(\mathrm{IC}_{50}=190 \mathrm{nM}\right)$. \\ Additionally, we provide evidence for the high antioxidant potential of MC in our \\ model. In conclusion, the present data substantiate the beneficial properties of \\ minocycline as promising neuroprotectant by its inhibitory activity on the \\ mitochondrial permeability transition pore.
}




\title{
Keywords
}

Primary cortical neurons; Rotenone; Mitochondrial permeability transition; Minocycline; Patch clamp

\begin{abstract}
Abbreviations
CsA, cyclosporin A; DFF, 2',7'-difluorofluorescein; DIV, days in vitro; DMEM, Dulbecco's Modified Eagle Medium; DMSO, dimethylsulfoxide; DPPH, 2,2-diphenyl1-picrylhydrazyl; Fluo-4 AM, fluo-4 pentaacetoxy-methylester; GFAP, glial fibrillary acid protein; HEPES, N-2-hydroxyethylpiperazine-N'-2-ethanesulfonic acid; MC, minocycline; mPTP, mitochondrial permeability transition pore; MTT, 3-[4,5-dimethylthiazol-2-yl]-2,5-diphenyl tetrazolium bromide; NMDA, N-methyl-D-aspartate; $\mathrm{P}_{\mathrm{o}}$, probability of being in the open state; PBS, phosphate-buffered saline; PD, Parkinson's disease; RLM, rat liver mitochondria; ROI, region of interest
\end{abstract}




\section{Introduction}

Minocycline (MC) is a semi-synthetic tetracycline derivative with proven and safe clinical track record and mainly used in the treatment of acne vulgaris [1]. Originally developed as an antibiotic with a broad-spectrum antibacterial activity, it shows biological effects, which are fundamentally different from its antimicrobial action. An increasing number of studies reported the potential use of $\mathrm{MC}$ as a cytoprotectant in the treatment of several neurological disorders including amyotropic lateral scerosis [2], multiple sclerosis [3], Alzheimer's disease [4], Huntigton's disease [5], Leber's hereditary optic neuropathy [6], and Parkinson's disease (PD) [7-9]. Furthermore, neuroprotective potency of MC has been observed in experimental models of acute cerebral ischemia [10, 11], spinal cord- [12-14] and traumatic brain injury [15]. But, also contradictory and even detrimental effects of MC were reported recently [16-20], pointing at the importance of a thorough understanding of the detailed cellular and molecular mechanisms triggered by MC.

It has been suggested that the observed protection conferred by MC is based on its anti-inflammatory and anti-oxidant properties, including the inhibition of matrix metalloproteases [21], blockade of inducible nitric oxide synthase [22], as well as free radical scavenging activity [23]. In addition, the MC-mediated neuroprotection is associated with a blockade of caspases, inhibition of MAP kinase, and prevention of cytochrome $\mathrm{c}$ release $[2,5,14,24]$. But, a direct involvement of $M C$ in mitochondrial permeability transition is still a matter of debate [25].

Mitochondrial dysfunction is widely accepted to contribute to degeneration processes in neurodegenerative diseases and neurotoxins impairing the oxidative phosporylation are used to create cellular and animal models for these disorders. One environmental toxin used in PD-related models is rotenone [26], a natural 
occurring complex keton. Due to its lipophilic character, rotenone crosses membranes freely and accumulates in cytoplasm and mitochondria [27] where it inhibits complex I of the mitochondrial respiratory chain by stopping the supply of electrons to quinol $\left(\mathrm{OH}_{2}\right)$-cytochrome c oxireductase [28]. This results in a dosedependent ATP-depletion, generation of free radicals, and finally apoptosis [29]. Although the rotenone model demonstrates potential relevance of the complex I deficit in PD pathogenesis, the mechanisms through which dysfunction of complex I might produce neurotoxicity are still unknown. It was reported that under pathological conditions of low ATP, oxidative stress, and high cytosolic calcium concentration the inner mitochondrial membrane permeability increases by formation of a large nonselective pore, the mitochondrial permeability transition pore (mPTP). The opening of this channel leads to an increase of the permeability to ions and small solutes of less than $1.5 \mathrm{kDa}$, resulting in mitochondrial swelling, depolarization, and a loss of membrane potential [30]. Concomitantly, the release of mitochondrial calcium ions as well as pro-apoptotic factors (e.g. apoptosis-inducing factor, cytochrome c) into the cytosol triggers signaling cascades leading to apoptosis and seems to cause neuronal decline in neurodegenerative diseases [31]. Here we study the pro-apoptotic permeability transition triggered by rotenone-induced complex I inhibition in cultivated cortical neurons with focus on the effect of MCapplication. Furthermore, we attempt to examine by single-channel measurements whether MC affects directly the formation/activity of the MPTP. 


\section{Materials and methods}

\subsection{Chemicals}

Cyclosporin A (CsA) and N-methyl-D-aspartate (NMDA) were obtained from Alexis (Lausen, Switzerland). If not especially mentioned, all other chemicals were purchased from Sigma (Steinheim, Germany). Stock solutions of rotenone (10 mM in DMSO) and MC (10 mM in appropriate water-based buffer) were prepared fresh daily. CsA (2 mM) was solubilized in $70 \%(\mathrm{v} / \mathrm{v})$ ethanol and stored at $4{ }^{\circ} \mathrm{C}$.

\subsection{Cell culture}

All procedures for animal use were in strict accordance with the Animal Health and Care Committee of the State of Saxony-Anhalt, Germany. The animals (Wistar rats, Harlan-Winkelmann, Borchen, Germany) were housed under controlled pathogenfree conditions with a cycle of $12 \mathrm{~h}$ light/12 h dark and food/water ad libitum. Rats were mated overnight and the following day was defined as embryonic day 1 (E1). Neuron-enriched cortical cultures were prepared from cerebral cortices of 16 days old rat embryos (E16). The cortices were removed, cleaned of meninges, and placed in Dulbecco's Modified Eagle Medium (DMEM; PAA Laboratories GmbH, Coelbe, Germany). After mechanical dispersion and centrifugation (5 min at $300 \mathrm{~g}$ ), the dissociated cells were plated onto poly-D-lysine-coated $(0.1 \mathrm{mg} / \mathrm{ml}$ in borate buffer, $\mathrm{pH} 8.4) 25 \mathrm{~mm}$ round glass coverslips placed in $35 \mathrm{~mm}$ culture dishes at a density of $1.5^{*} 10^{6}$ cells $/ 2 \mathrm{ml}$ in DMEM medium with $2 \%$ B-27 (serum-free supplement, Invitrogen, Karlsruhe, Germany). Cells were maintained 13 days in vitro (13. DIV) in a 
humidified $5 \% \mathrm{CO}_{2} / 95 \%$ air atmosphere at $37{ }^{\circ} \mathrm{C}$. Culture medium was replaced by DMEM without B-27 supplement $24 \mathrm{~h}$ before use. Immunohistochemical characterization of the cultures was performed using the primary SMI311-antibody (1:1000; Convance, Berkely, USA) and GFAP-antibody (1:5000; Santa Cruz Biotechnology, Santa Cruz, USA) to detect neurons and astrocytes, respectively. Briefly, cells were fixed (4\% paraformaldehyde, $20 \mathrm{~min}$ ) and incubated in blocking solution (10 \% donkey normal serum, $0.3 \%$ Triton $\mathrm{X}-100,0.1 \%$ sodium azide) for $30 \mathrm{~min}$ followed by the application of the respective primary antibody (overnight at $4{ }^{\circ} \mathrm{C}$ ). After washing with PBS containing $0.1 \%$ Triton $\mathrm{X}-100$ the cells were sequentially incubated with the respective secondary antibody (1:1000, Cy2conjugated anti-mouse-lgG, Rockland, Gilbertsville, USA; Cy3-conjugated anti-goatIgG, Dianova, Hamburg, Germany) for 2-3 h, mounted, and examined on a confocal fluorescence microscope (AXIOVERT 100M, LSM PASCAL, Zeiss, Jena, Germany).

\subsection{Cell viability assay}

Cell viability was assayed using MTT (3-(4,5-dimethylthiazol-2-yl)-2,5diphenyltetrazolium bromide), a yellow tetrazolium salt, which is reduced to purple water-insoluble formazan by active cells. Cortical neurons were treated with different concentrations of rotenone (100 pM, $500 \mathrm{pM}, 1 \mathrm{nM}, 5 \mathrm{nM}$, and $10 \mathrm{nM})$ for $24 \mathrm{~h}$. The medium was replaced by $1 \mathrm{ml}$ PBS containing $1 \mathrm{mg} \mathrm{MTT}$ and incubated at $37^{\circ} \mathrm{C}$ for $1 \mathrm{~h}$. Afterwards, cells were permeabilized by DMSO and the extent of reduction of MTT to formazan within the cells was measured spectrophotometrically (Lambda 2, PerkinElmer, Norwalk, USA) at an absorbance of $570 \mathrm{~nm}$. 


\subsection{Intracellular calcium measurements}

Intracellular calcium concentrations were recorded by live cell imaging using cortical cultures grown on glass coverslips for 13 DIV. After 45 min incubation with $2.5 \mu \mathrm{M}$ fluo-4 pentaacetoxy-methylester (Fluo-4 AM; Invitrogen, Karlsruhe, Germany) the coverslips were placed in a stainless steel chamber (Attofluor, $2 \mathrm{ml}$ volume, Molecular probes, Leiden, The Netherlands) and mounted on a thermostatically controlled stage $\left(37^{\circ} \mathrm{C}\right)$ of an inverted confocal fluorescence microscope (AXIOVERT 100M, LSM PASCAL, Zeiss, Jena, Germany). Cultures were superfused ( $1 \mathrm{ml} / \mathrm{min}$ ) with HEPES-buffer (140 mM NaCl, $5 \mathrm{mM} \mathrm{KCl,} 2 \mathrm{mM} \mathrm{CaCl} 2,10 \mathrm{mM}$ glucose, and $10 \mathrm{mM}$ HEPES, pH 7.47) for at least 2 min (baseline) followed by subsequent stimulation with $200 \mu \mathrm{M}$ NMDA to induce an acute increase of cytosolic $\mathrm{Ca}^{2+}$. Investigated drugs or vehicle (DMSO and Ethanol) were consistently applied 30 min before and during the $\mathrm{Ca}^{2+}$-measurements. Fluorescent images (excitation $488 \mathrm{~nm}$ and emission $>505 \mathrm{~nm}$ ) were captured sequentially (10 s intervals) and experimental settings (including intensity of the laser, pinhole diameter, detector gain) were kept uniform in all compared experiments. The fluorescence intensity data, obtained as average intensity within regions of interest (ROIs over the somata of about 10-25 individual cells), were quantified using the Zeiss LSM software. After subtraction of a background noise the average of all analyzed cells of one experiment $(n=1)$ were used. The means of 5 time point values before a subsequent addition of NMDA or at the end of the experiment were used for statistical analysis. One way ANOVA followed by Dunnett T3 (SPSS Version 15.0.1.1) was performed to asses the differences between the groups. 


\subsection{Isolation of rat liver mitochondria, preparation of mitoplasts, and electrophysiology}

Rat liver mitochondria (RLM) were prepared as described previously [32] and the concentration of mitochondrial protein was determined by using the Biuret method. RLM were used for preparing mitoplasts i.e. fragile vesicles consisting of inner mitochondrial membrane after rupture of the outer membrane. They can be recognized by their absolutely round shape and one (in liver mitoplasts) dark spot. From mitoplasts single-channel currents were recorded by patch-clamp methods as explained in detail, previously [33]. Mitoplasts were obtained by hyposmotic shock: the ionic strength was lowered 10-fold by addition of a hypotonic medium (5 mM KHEPES, $0.2 \mathrm{mM} \mathrm{CaCl}_{2}, \mathrm{pH}$ 7.2). After one minute incubation at room temperature, isotonicity was restored by addition of hypertonic medium $(750 \mathrm{mM} \mathrm{KCl}, 80 \mathrm{mM} \mathrm{K}$ HEPES, $0.2 \mathrm{mM} \mathrm{CaCl}_{2}, \mathrm{pH}$ 7.2).

For patch-clamp experiments borosilicate glass pipettes (Harvard Apparatus, Fircroft, Kent, UK) were polished to yield resistances of 10-15 M 2 . Free-floating mitoplasts were "chased" by means of an electrically driven micromanipulator and moved to their final position at the pipette tip by gentle suction. Gigaseals of $0.7-1.5 \mathrm{G} \Omega$ formed spontaneously in about $25 \%$ of the trials, and currents were recorded by means of an EPC-7 amplifier (HEKA electronics, Lambrecht, Germany). Currents were lowpass filtered by a 4-pole Bessel filter at a corner frequency of $0.5 \mathrm{kHz}$. Data were recorded at a sample frequency of $4 \mathrm{kHz}$ by means of the pClamp9.2 software (Axon instruments, Foster City, USA) which was also used for processing of the data. The measuring pipette was filled with HEPES-buffer $(150 \mathrm{mM} \mathrm{KCl}, 0.3 \mathrm{mM} \mathrm{CaCl} 2,20 \mathrm{mM}$ K-HEPES, $\mathrm{pH} 7.2)$. Experiments were carried out at room temperature $\left(25 \pm 1{ }^{\circ} \mathrm{C}\right)$. 
Test solutions were based on the HEPES-buffer and were applied through the glass capillaries of a peristaltic-pump driven flow system. Potentials are given as at the inner side of the membrane. Inward currents always deflect downward. The probability that the channel is in an open state $\left(P_{o}\right)$ was determined by all-points analysis according to Loupatatzis et al. [34]. To the equation for fitting the doseresponse curve by Michaelis-Menten kinetics, a term $A$ was added accounting for a seemingly incomplete blockade of the mPTP in the early phase of the experiment. We collected the data in segments of one minute then dividing the mean of 6 segments in MC (skipping always the first) by the mean of 3 segments before MC as the normalized $\mathrm{P}_{\mathrm{o}}$. As development of the $\mathrm{MC}$ block took more than a minute, $A$ accounts for the contribution of early records with incomplete blockade. Best fitting values were determined by means of the ENZFIT software.

\subsection{Mitochondrial swelling and cytochrome $c$ release from isolated mitochondria}

Swelling experiments on RLM ( $0.5 \mathrm{mg}$ protein $/ \mathrm{ml})$ were performed in sucrose-based buffer (200 mM sucrose, 10 mM Tris, 1 mM KH${ }_{2} \mathrm{PO}_{4}, 10 \mu \mathrm{M}$ EGTA, 5 mM glutamate, and $5 \mathrm{mM}$ malate, $\mathrm{pH} 7.2)$ and the decrease in light absorbance $(620 \mathrm{~nm})$ was recorded using a multiplate reader (Titertek Plus MS212, ICN, Frankfurt, Germany). RLM were pre-incubated with the investigated drugs or vehicle (ethanol) prior to stimulation with $100 \mu \mathrm{M} \mathrm{Ca}^{2+}$. Afterwards, the release of cytochrome $\mathrm{c}$ into the buffer was determined by standard immunoblotting [6] using cytochrome c antibody (7H8.2C12, 1:500; BD Pharmingen, San Diego, USA). 


\subsection{Intracellular oxidative stress assay}

The intracellular oxidative stress assay was performed according the DFF-imaging procedure published previously [6]. Briefly, cortical cultures were incubated with $100 \mu \mathrm{M} \mathrm{H}$ 2DFF-DA (5-(and-6)-carboxy-2',7'-difluorodihydrofluorescein diacetate; Invitrogen, Karlsruhe, Germany) at $37^{\circ} \mathrm{C}$ in a humidified $5 \% \mathrm{CO}_{2}$ atmosphere for $60 \mathrm{~min}$. The investigated drugs or vehicle (PBS) were applied $30 \mathrm{~min}$ prior to stimulation with $100 \mu \mathrm{M} \mathrm{H}_{2} \mathrm{O}_{2}$. The fluorescence intensity data, obtained as average intensity within ROls over the somata of individual cells, were quantitatively analyzed using the Zeiss LSM software.

\subsection{DPPH radical scavenging assay}

The free-radical scavenging activity was determined by a procedure reported previously [35]. Briefly, DPPH (2,2-diphenyl-1-picrylhydrazyl; Fluka, Steinheim, Germany) was dissolved in $80 \%$ methanol in water to a final concentration of $100 \mu \mathrm{M}$. The reactions were initiated by adding different concentrations of the tested drugs or of the vehicle (DMSO), incubated at $37^{\circ} \mathrm{C}$ for $30 \mathrm{~min}$. The absorbance was measured at $516 \mathrm{~nm}$ (Lambda 2, PerkinElmer, Norwalk, USA). 


\section{Results}

\subsection{Rotenone induces calcium deregulation in primary cortical neurons}

In order to evaluate an adequate rotenone concentration that affected cortical neurons without inducing complete cell death, a colorimetric MTT-reduction assay was performed. Treatment with 100 pM, 500 pM, 1 nM, 5 nM, or $10 \mathrm{nM}$ rotenone for $24 \mathrm{~h}$ resulted in a reduced formazan production of $89.0 \pm 6.3 \%, 81.9 \pm 14.0 \%$, $72.3 \pm 9.5 \%, 59.8 \pm 1.8 \%$, and $45.8 \pm 1.1 \%$, respectively, with statistical significance at concentrations of 5 and $10 \mathrm{nM}(p<0,05$; Fig. 1A). The application of $10 \mathrm{nM}$ rotenone for $24 \mathrm{~h}$ resulted in a cell survival of about $50 \%$. This concentration was used in the following experiments.

For evaluation of the involvement of the mitochondrial permeability transition pore (mPTP) in rotenone-mediated toxicity, changes of intracellular calcium were recorded in cortical neurons using the $\mathrm{Ca}^{2+}$-imaging technique. The neuronal cultures from dissociated $\mathrm{E} 16$ rat cortices after 13 days in vitro (13 DIV) consist of a large population of neurons and single astroglia cells (Fig. 1B). Stimulation of these primary neurons with $200 \mu \mathrm{M}$ NMDA for 2 min caused an increase of the Fluo-4 fluorescence immediately after the exposure. Within 5 min after NMDA stimulation, intensity returned to the basal level. The response of cell cultures after 13 DIV was stable and could be repeated by subsequent NMDA applications. This also indicates the viability of the cells during live cell imaging experiments (Fig. 2A). Treatment with $10 \mathrm{nM}$ rotenone $30 \mathrm{~min}$ before and over the complete period of the experiment did not affect the amplitude of the $\mathrm{Ca}^{2+}$-rise in cortical neurons. However, the fluorescence signal in the rotenone-treated groups did not return back to baseline levels after NMDA exposure as was the case in control cells (Fig. 2B). This $\mathrm{Ca}^{2+}$ - 
deregulation became more obvious after repeated stimulations ( 2 to 3 times) with NMDA (Fig. 2C, D). In presence of both the mPTP inhibitor cyclosporin A (CsA, $2 \mu \mathrm{M})$ and rotenone, the observed $\mathrm{Ca}^{2+}$-deregulation was alleviated by $37.6 \%$. This indicates an involvement of mPTP-opening under these conditions (Fig. 2D).

\subsection{MC protects neurons against rotenone-induced $\mathrm{Ca}^{2+}$-deregulation}

Simultaneous application of rotenone and $100 \mu \mathrm{M}$ MC decreased the rotenoneinduced $\mathrm{Ca}^{2+}$-deregulation. The analysis of the basal levels of cytosolic $\mathrm{Ca}^{2+}$ after the second stimulus did not show significant deviation after the application of MC (Fig. 2C). However, after MC treatment the final baseline of the $\mathrm{Ca}^{2+}$-signal was significantly decreased by $60.9 \%$ as compared with the rotenone-treated group after three NMDA stimuli (Fig. 2D). Thus, after repeated stimulations and transient rises of $\mathrm{Ca}^{2+}$ the presence of $\mathrm{MC}$ protected the cells from a Ca${ }^{2+}$-deregulation. Additionally, MC was more efficient than the MPTP inhibitor CsA at the tested concentration.

\subsection{Patch Clamp experiments reveal blocking of the MPTP by MC}

The most direct test for a possible blocking effect of MC on the MPTP is the singlechannel experiment studying mitoplast membranes by patch-clamp techniques. The predominant channel of such patches showed a single-channel conductance of more than $1 \mathrm{nS}$, could be dose-dependently blocked by CsA, and was characterized by multiple substrates [34]. Patches demonstrating corresponding single-channel behavior were transferred to a pipe of the flow system that contained test solution with different concentrations of MC. Within 1-2 min the $P_{o}$ declined to a lower level 
(Fig. 3A) determined by all-points analysis as explained in methods. Inhibition was concentration dependent and could be described by Michaelis-Menten kinetics with a $I_{50}$ of $190 \mathrm{nM}$ and a value $A$ of 0.27 (Fig. 3B). In 4 out of 6 experiments with a strong MC effect MPTP inhibition was partly reversible when switching to an isotonic control solution. Thus, MC is able to inhibit the MPTP on the single-channel level.

\subsection{MC abolishes $\mathrm{Ca}^{2+}$-induced swelling and cytochrome $c$ release in isolated $R L M$}

Investigations on isolated RLM proved, that MC $(100 \mu \mathrm{M})$ was able to inhibit swelling induced by $\mathrm{Ca}^{2+}$ as measured by a reduced change of light absorbance (Fig. 4A). Immunoblotting of the extra-mitochondrial fractions revealed that $\mathrm{MC}$ abolished the $\mathrm{Ca}^{2+}$-induced release of cytochrome $\mathrm{c}$ in RLM (Fig. 4B). Furthermore, MC triggered a weak release of cytochrome $\mathrm{c}$ (without $\mathrm{Ca}^{2+}$ ) under the tested conditions (Fig. 4B, lane 1) which was comparable to the cytochrome c release observed after cotreatment with $\mathrm{Ca}^{2+}$ (Fig. 4B, lane 5). In contrast to the data obtained by immunoblotting, no swelling of MC-treated RLM (without $\mathrm{Ca}^{2+}$ ) was observed (data not shown).

\subsection{MC shows antioxidant activity inside the cells and is a powerful radical scavenger}

Oxidative stress plays an important role in mitochondrial permeability transition [30, 36]. To examine a possible antioxidant capacity of $\mathrm{MC}$ in our cortical culture, cells were preloaded with $\mathrm{H}_{2}$ DFF-DA and the resulting DFF-fluorescence was measured. 
The basal level of DFF fluorescence in untreated cells increased significantly after $\mathrm{H}_{2} \mathrm{O}_{2}(100 \mu \mathrm{M})$ exposure. Pre-treatment with $100 \mu \mathrm{M} \mathrm{MC}$ abolished the increase of the fluorescence signal (Fig. 5A), demonstrating the antioxidant activity of MC inside the cells.

In order to assess the general radical scavenging potency of MC, we used an assay that detected the reaction of the drug with $\mathrm{DPPH}$, a stable artificial free radical. MC is an effective scavenger for DPPH as indicated by the concentration dependent decrease in light absorbance. The scavenging capacity is comparable with that of the well known radical scavenger L-ascorbic acid (Fig. 5B). 


\section{Discussion}

It was our working hypothesis that treatment of cultivated cortical neurons with the pesticide rotenone results in a disruption of the mitochondrial oxidative phosphorylation chain by inhibition of complex I and hence elevation of reactive oxygen species (ROS). Together with a high cytosolic calcium concentration, which in turn induces formation and opening of the mitochondrial permeability transition pore (mPTP), the release of pro-apoptotic factors is triggered. According to this "twohit" hypothesis [36], we established a cell culture model of neuronal damage in order to test a possible inhibitory effect of the tetracycline derivative minocycline (MC) on the induced mPTP-opening.

After chronic administration to rats rotenone reproduced some features of Parkinson's disease (PD) [26, 29] and also triggered degeneration in cultured PC-12 cells [37]. Based on these observations, and due to the well-defined chemical property of rotenone as complex I inhibitor, we used this drug as inducer for neuronal degeneration in our cell culture model. It turned out that cortical neurons of embryonic rats cultivated for two weeks were highly sensitive to rotenone. This effect was dose-dependent with a $L D_{50}$ of around $10 \mathrm{nM}$. The cells were affected in their respiratory activity but without being committed to complete cell death. This result is in contrast to other studies, in which 50-times higher concentrations of rotenone $(0.5 \mu \mathrm{M})$ were required for neuronal decline [38]. A possible explanation could be a different cultivation method (application of the cytotoxic cytosine arabinoside) and the lower age of the cultures in their study.

In our study, subsequent application of NMDA induced neuronal $\mathrm{Ca}^{2+}$-overload in the cells. Under these conditions the $\mathrm{Ca}^{2+}$-equilibrium across the inner mitochondrial 
membrane is shifted and mitochondria take up $\mathrm{Ca}^{2+}$ from the cytoplasm. This leads to a stimulation of the respiratory chain and to an increase in ROS generation, particularly in the presence of the complex I inhibitor rotenone. As a result, the MPTP opens [39], the mitochondrial potential collapses, and $\mathrm{Ca}^{2+}$ is released into the cytosol [40]. Such a $\mathrm{Ca}^{2+}$-deregulation could be detected in rotenone-treated cells during live cell calcium imaging. An involvement of the MPTP in the model is strongly supported by the observed effect of the well-known mPTP inhibitor CsA, which alleviated the $\mathrm{Ca}^{2+}$-deregulation. This immune suppressive cyclic peptide binds to cyclophiline $\mathrm{D}$, a compound of the mPTP-complex, and prevents opening [41, 42]. However, the rotenone-mediated $\mathrm{Ca}^{2+}$-deregulation is not entirely normalized by CsA, indicating that other mechanisms are playing an additional role. In contrast to $\mathrm{CsA}$, the antibiotic MC was more effective to abolish the $\mathrm{Ca}^{2+}$-deregulation mediated by rotenone. This potential of MC to protect cells with defect complex I is in accordance with a recent publication, wherein a malfunction of the respiratory chain was initiated by point mutation of the mitochondrial DNA [6]. The ability of MC to inhibit the formation of mPTP was also reported from groups focusing on isolated brain and liver mitochondria [2, 43]. In contrast, Mansson et al. did not show a direct inhibition of the mPTP in isolated brain mitochondria [25]. To clarify this issue, we measured single-channel currents through the MPTP of mitoplasts. To our knowledge, we show for the first time a blocking effect of MC on the MPTP by patch clamp, indicating a direct interaction of $\mathrm{MC}$ with the mega pore. It must be noted, however, that a mitoplast constitutes an artificial system in that the outer membrane is missing and, secondly, the mitochondrial membrane potential is lost. Nevertheless, mitoplasts have been proved to be useful tools to study successfully biophysical questions and direct pharmacological interactions with the channel proteins in the inner membrane $[33,34]$. Additionally, it is remarkable that inhibition of the MPTP can 
be observed at relatively high $\mathrm{Ca}^{2+}$-concentrations. As calcium ions are known to activate the pore, the concentration of $\mathrm{MC}$ required for a full block are possibly even lower at lower $\mathrm{Ca}^{2+}$-concentrations. The higher concentrations used here are necessary for establishing stable membrane patches at the tip of the measuring pipette.

The easier accessibility of the pore in mitoplasts for large modulating molecules as compared with intact mitochondria, the extremely sensitive measurement of the activity of single pores, and the high lipophilicity of MC [44] may be explanations for the observation that blockade of the MPTP required considerably lower MC concentrations in the patch-clamp experiments. Similarly, lower effective concentrations in mitoplast experiments than in experiments on intact mitochondria were reported before [33].

It has been considered that tetracyclines, including $\mathrm{MC}$, can chelate $\mathrm{Ca}^{2+}$. However, the presumable influence of $\mathrm{MC}$ on the extracellular $\mathrm{Ca}^{2+}$ concentration (e.g. in the intracellular calcium measurements) may be neglected because of the much higher concentration of $\mathrm{Ca}^{2+}$ in relation to $\mathrm{MC}$ in the buffer used.

Our data confirm earlier reports about the ability of $\mathrm{MC}$ to inhibit $\mathrm{Ca}^{2+}$-induced swelling of rat liver mitochondria [43]. Additionally, the observed decrease of $\mathrm{Ca}^{2+}-$ triggered release of cytochrome $\mathrm{c}$ in the presence of $\mathrm{MC}$ supports previously reported protective effects of MC on the MPTP. A remarkable result was the finding that MC per se induced a weak release of cytochrome $\mathrm{c}$ without any detectable mitochondrial swelling. This observation may perhaps be an explanation for the observed detrimental effects of MC [16, 18-20] and requires further clarification.

Due to the fact that the observed changes of the intracellular $\mathrm{Ca}^{2+}$-dynamics caused by rotenone could not be abolished completely by the mPTP-inhibitor CsA other mechanisms than mPTP-opening may play a role. The higher potential of MC, as 
compared to $\mathrm{CsA}$, to normalize the rotenone-triggered $\mathrm{Ca}^{2+}$-deregulation may be

explained by the antioxidant properties of MC. This was also proved in our experiments on cortical neurons after $\mathrm{H}_{2} \mathrm{O}_{2}$-induction. Using a cell-free assay of antioxidant-potency, our obtained data confirm additionally that MC is a direct antioxidant [23] with a comparable potential as L-ascorbic acid.

In conclusion, rotenone-induced $\mathrm{Ca}^{2+}$-deregulation of cultivated cortical neurons is mediated by mitochondrial permeability transition. The promising cytoprotectant MC is able to counteract this process. We show here a direct inhibitory interaction of MC with the MPTP and confirm the high antioxidant potential of this multifaceted tetracycline derivative. These findings point out the potential of $\mathrm{MC}$ for the treatment of disorders related to oxidative stress and/or increased mPTP-opening in general. It must be noted, however, that there are clear indications for additional detrimental effects of MC, which makes the clinical application of MC rather doubtful [20]. Therefore, further investigations needed for clarification of the negative action of MC. 


\section{References}

1. Goulden V, Glass D, Cunliffe WJ, Safety of long-term high-dose minocycline in the treatment of acne. Br J Dermatol. 134(4): 693-5., 1996.

2. Zhu S, Stavrovskaya IG, Drozda M, Kim BY, Ona V, Li M, et al., Minocycline inhibits cytochrome c release and delays progression of amyotrophic lateral sclerosis in mice. Nature 417(6884): 74-8, 2002.

3. Brundula V, Rewcastle NB, Metz LM, Bernard CC, Yong VW, Targeting leukocyte MMPs and transmigration: minocycline as a potential therapy for multiple sclerosis. Brain 125(Pt 6): 1297-308, 2002.

4. Choi Y, Kim HS, Shin KY, Kim EM, Kim M, Park CH, et al., Minocycline attenuates neuronal cell death and improves cognitive impairment in Alzheimer's disease models. Neuropsychopharmacology 32(11): 2393-404, 2007.

5. Chen M, Ona VO, Li M, Ferrante RJ, Fink KB, Zhu S, et al., Minocycline inhibits caspase- 1 and caspase- 3 expression and delays mortality in a transgenic mouse model of Huntington disease. Nat Med 6(7): 797-801, 2000.

6. Haroon MF, Fatima A, Scholer S, Gieseler A, Horn TF, Kirches E, et al., Minocycline, a possible neuroprotective agent in Leber's hereditary optic neuropathy (LHON): Studies of cybrid cells bearing 11778 mutation. Neurobiol Dis 28: 237-250, 2007.

7. Du Y, Ma Z, Lin S, Dodel RC, Gao F, Bales KR, et al., Minocycline prevents nigrostriatal dopaminergic neurodegeneration in the MPTP model of Parkinson's disease. Proc Natl Acad Sci U S A 98(25): 14669-74, 2001.

8. He Y, Appel S, Le W, Minocycline inhibits microglial activation and protects nigral cells after 6-hydroxydopamine injection into mouse striatum. Brain Res 909(1-2): 187-93, 2001. 
9. Wu DC, Jackson-Lewis V, Vila M, Tieu K, Teismann P, Vadseth C, et al., Blockade of microglial activation is neuroprotective in the 1-methyl-4-phenyl1,2,3,6-tetrahydropyridine mouse model of Parkinson disease. J Neurosci 22(5): 1763-71, 2002.

10. Yrjanheikki J, Keinanen R, Pellikka M, Hokfelt T, Koistinaho J, Tetracyclines inhibit microglial activation and are neuroprotective in global brain ischemia. Proc Natl Acad Sci U S A 95(26): 15769-74, 1998.

11. Yrjanheikki J, Tikka T, Keinanen R, Goldsteins G, Chan PH, Koistinaho J, A tetracycline derivative, minocycline, reduces inflammation and protects against focal cerebral ischemia with a wide therapeutic window. Proc Natl Acad Sci U S A 96(23): 13496-500, 1999.

12. Stirling DP, Khodarahmi K, Liu J, McPhail LT, McBride CB, Steeves JD, et al., Minocycline treatment reduces delayed oligodendrocyte death, attenuates axonal dieback, and improves functional outcome after spinal cord injury. J Neurosci 24(9): 2182-90, 2004.

13. Wells JE, Hurlbert RJ, Fehlings MG, Yong VW, Neuroprotection by minocycline facilitates significant recovery from spinal cord injury in mice. Brain 126(Pt 7): 1628-37, 2003.

14. Teng YD, Choi H, Onario RC, Zhu S, Desilets FC, Lan S, et al., Minocycline inhibits contusion-triggered mitochondrial cytochrome c release and mitigates functional deficits after spinal cord injury. Proc Natl Acad Sci U S A 101(9): 30716, 2004.

15. Sanchez Mejia RO, Ona VO, Li M, Friedlander RM, Minocycline reduces traumatic brain injury-mediated caspase-1 activation, tissue damage, and neurological dysfunction. Neurosurgery 48(6): 1393-9; discussion 1399-401, 2001. 
16. Cornet S, Spinnewyn B, Delaflotte S, Charnet C, Roubert V, Favre C, et al., Lack of evidence of direct mitochondrial involvement in the neuroprotective effect of minocycline. Eur J Pharmacol 505(1-3): 111-9, 2004.

17. Diguet E, Gross CE, Tison F, Bezard E, Rise and fall of minocycline in neuroprotection: need to promote publication of negative results. Exp Neurol 189(1): 1-4, 2004.

18. Fernandez-Gomez FJ, Gomez-Lazaro M, Pastor D, Calvo S, Aguirre N, Galindo MF, et al., Minocycline fails to protect cerebellar granular cell cultures against malonate-induced cell death. Neurobiol Dis 20(2): 384-91, 2005.

19. Keilhoff G, Langnaese K, Wolf G, Fansa H, Inhibiting effect of minocycline on the regeneration of peripheral nerves. Dev Neurobiol 67(10): 1382-95., 2007.

20. Gordon PH, Moore DH, Miller RG, Florence JM, Verheijde JL, Doorish C, et al., Efficacy of minocycline in patients with amyotrophic lateral sclerosis: a phase III randomised trial. Lancet Neurol. 6(12): 1045-53, 2007.

21. Golub LM, Lee HM, Ryan ME, Giannobile WV, Payne J, Sorsa T, Tetracyclines inhibit connective tissue breakdown by multiple non-antimicrobial mechanisms. Adv Dent Res 12(2): 12-26, 1998.

22. Amin AR, Attur MG, Thakker GD, Patel PD, Vyas PR, Patel RN, et al., A novel mechanism of action of tetracyclines: effects on nitric oxide synthases. Proc Natl Acad Sci U S A 93(24): 14014-9, 1996.

23. Kraus RL, Pasieczny R, Lariosa-Willingham K, Turner MS, Jiang A, Trauger JW, Antioxidant properties of minocycline: neuroprotection in an oxidative stress assay and direct radical-scavenging activity. Journal of Neurochemistry 94(3): 819-27, 2005.

24. Wang X, Zhu S, Drozda M, Zhang W, Stavrovskaya IG, Cattaneo E, et al., Minocycline inhibits caspase-independent and -dependent mitochondrial cell 
death pathways in models of Huntington's disease. Proc Natl Acad Sci U S A 100(18): 10483-7, 2003.

25. Mansson R, Hansson MJ, Morota S, Uchino H, Ekdahl CT, Elmer E, Reevaluation of mitochondrial permeability transition as a primary neuroprotective target of minocycline. Neurobiol Dis 25(1): 198-205, 2007.

26. Betarbet R, Sherer TB, MacKenzie G, Garcia-Osuna M, Panov AV, Greenamyre JT, Chronic systemic pesticide exposure reproduces features of Parkinson's disease. Nat Neurosci 3(12): 1301-6, 2000.

27. Talpade DJ, Greene JG, Higgins DS, Jr., Greenamyre JT, In vivo labeling of mitochondrial complex I (NADH:ubiquinone oxidoreductase) in rat brain using [(3)H]dihydrorotenone. J Neurochem 75(6): 2611-21, 2000.

28. Degli Esposti M, Inhibitors of NADH-ubiquinone reductase: an overview. Biochim Biophys Acta 1364(2): 222-35, 1998.

29. Sherer TB, Betarbet R, Testa CM, Seo BB, Richardson JR, Kim JH, et al., Mechanism of toxicity in rotenone models of Parkinson's disease. J Neurosci 23(34): 10756-64, 2003.

30. Crompton $\mathrm{M}$, The mitochondrial permeability transition pore and its role in cell death. Biochem J 341 (Pt 2): 233-49, 1999.

31. Halestrap AP, Calcium, mitochondria and reperfusion injury: a pore way to die. Biochem Soc Trans 34(Pt 2): 232-7, 2006.

32. Kupsch K, Parvez S, Siemen D, Wolf G, Modulation of the permeability transition pore by inhibition of the mitochondrial K(ATP) channel in liver vs. brain mitochondria. J Membr Biol 215(2-3): 69-74., 2007.

33. Sayeed I, Parvez S, Winkler-Stuck K, Seitz G, Trieu I, Wallesch CW, et al., Patch clamp reveals powerful blockade of the mitochondrial permeability transition pore by the D2-receptor agonist pramipexole. Faseb J 20(3): 556-8, 2006. 
34. Loupatatzis C, Seitz G, Schonfeld P, Lang F, Siemen D, Single-channel currents of the permeability transition pore from the inner mitochondrial membrane of rat liver and of a human hepatoma cell line. Cell Physiol Biochem 12(5-6): 269-78, 2002.

35. Lorenz P, Roychowdhury S, Engelmann M, Wolf G, Horn TF, Oxyresveratrol and resveratrol are potent antioxidants and free radical scavengers: effect on nitrosative and oxidative stress derived from microglial cells. Nitric Oxide 9(2): 64-76, 2003.

36. Brookes PS, Yoon Y, Robotham JL, Anders MW, Sheu SS, Calcium, ATP, and ROS: a mitochondrial love-hate triangle. Am J Physiol Cell Physiol 287(4): C81733, 2004.

37. Hartley A, Stone JM, Heron C, Cooper JM, Schapira AH, Complex I inhibitors induce dose-dependent apoptosis in PC12 cells: relevance to Parkinson's disease. J Neurochem 63(5): 1987-90, 1994.

38. Pei W, Liou AK, Chen J, Two caspase-mediated apoptotic pathways induced by rotenone toxicity in cortical neuronal cells. Faseb J 17(3): 520-2, 2003.

39. Takeyama N, Matsuo N, Tanaka T, Oxidative damage to mitochondria is mediated by the $\mathrm{Ca}(2+)$-dependent inner-membrane permeability transition.

Biochem J 294 ( Pt 3): 719-25, 1993.

40. Dahlem YA, Wolf G, Siemen D, Horn TF, Combined modulation of the mitochondrial ATP-dependent potassium channel and the permeability transition pore causes prolongation of the biphasic calcium dynamics. Cell Calcium 39(5): 387-400, 2006.

41. Halestrap AP, Connern CP, Griffiths EJ, Kerr PM, Cyclosporin A binding to mitochondrial cyclophilin inhibits the permeability transition pore and protects 
hearts from ischaemia/reperfusion injury. Mol Cell Biochem 174(1-2): 167-72, 1997.

42. Zoratti M, Szabo I, De Marchi U, Mitochondrial permeability transitions: how many doors to the house? Biochim Biophys Acta 1706(1-2): 40-52, 2005.

43. Fernandez-Gomez FJ, Galindo MF, Gomez-Lazaro M, Gonzalez-Garcia C, Cena $\mathrm{V}$, Aguirre N, et al., Involvement of mitochondrial potential and calcium buffering capacity in minocycline cytoprotective actions. Neuroscience 133(4): 959-67, 2005.

44. Allen JC, Minocycline. Ann Intern Med 85(4): 482-7, 1976.

\section{Acknowledgements}

The support and helpful discussions of Dr S. Kropf (Institute of Biometry and Medical Informatics, Magdeburg) and Dr P. Schönfeld (Institute of Biochemistry, Magdeburg) are gratefully appreciated. We thank H. Baumann and H. Goldammer for their expert technical assistance. This work was supported by grants from the German Federal Ministry of Education and Research (BMBF 01ZZ0407). 


\section{Figure legends:}

\section{Fig. 1.}

Rotenone decreases cell viability of primary cortical cell cultures. (A) Primary cortical cultures were treated for $24 \mathrm{~h}$ with different concentrations of rotenone. Cell viability was detected via MTT-reduction (see materials and methods). Data in percent of controls shown as means \pm S.E.M. $(n=3)$. Statistical significance between rotenonetreated and untreated cells are indicated $\left({ }^{*} p<0.05,{ }^{* *} p<0.01\right)$.

(B) Immunohistochemical analysis of the primary cortical cell culture by using the neurofilament marker SMI311 (green) and GFAP (red) demonstrate the existence of neurons at 13 DIV (bar $20 \mu \mathrm{m}$, representative image).

\section{Fig. 2.}

Stimulation of primary cortical cell cultures with NMDA (200 $\mu \mathrm{M}, 3$ times) leads to an elevated $\mathrm{Ca}^{2+}$-concentration that was reversed during wash-out. $(\mathrm{A})$ Imaging of intracellular $\mathrm{Ca}^{2+}$-dynamics without drug (Vehicle, triangle), after application of $10 \mathrm{nM}$ rotenone alone (black) and in combination with $2 \mu \mathrm{M}$ CsA (grey cross) or $100 \mu \mathrm{M}$ MC (grey circle). Presented are means $(n=5)$ of Fluo-4 fluorescence intensities normalized to the highest signal $(100 \%)$. Statistical analysis of the intracellular $\mathrm{Ca}^{2+}-$ signals after the first $(B)$, after the second $(C)$, and after the third stimulus of NMDA (D). Data are shown as normalized means \pm S.E.M. $(n=5)$. Acute treatment of $10 \mathrm{nM}$ rotenone led to a calcium deregulation in primary cortical neurons. Simultaneous application of the mPTP-inhibitor CsA partially protected neurons from a rotenoneinduced calcium deregulation, indicating involvement of the MPTP. In presence of MC this effect was more pronounced. 


\section{Fig. 3.}

MC inhibits the mPTP of liver mitoplasts. (A) Single channel records from a mitoplast before, $403 \mathrm{~s}$ after switching to a high $(10 \mu \mathrm{M}) \mathrm{MC}$ concentration, and $317 \mathrm{~s}$ after returning to an isotonic control solution. Dashed lines and arrows are giving the closed state of the MPTP. MC reduced the open probability and the effect is irreversible at this relatively high concentration. (B) The blocking effect of $\mathrm{MC}$ on the mPTP of liver mitoplasts is dose dependent. Dose-response relation measured at 5 different concentrations of MC by single-channel experiments. The measuring points give the normalized $P_{0}( \pm$ S.E.M.) determined by all-point analysis and were fitted best by Michaelis-Menten kinetics (continuous curve) with a $\mathrm{IC}_{50}$ of $190 \mathrm{nM}$ and a factor $A=0.27$ (for significance of $A$ see methods). The point used as the normalized zero-concentration was taken from the mean of the $\mathrm{P}_{\mathrm{o}}$ of the 3 min preceding application of MC for each of 7 experiments.

\section{Fig. 4.}

$\mathrm{MC}$ inhibits $\mathrm{Ca}^{2+}$-induced swelling and it modulates the release of cytochrome $\mathrm{c}$ in RLM. (A) Swelling was measured in sucrose-based buffer as decrease in light absorbance induced by $100 \mu \mathrm{M} \mathrm{Ca}^{2+}$. After establishing a baseline the investigated drugs were applied (black arrow). Pre-incubation with CsA (1 $\mu \mathrm{M})$ completely inhibited the $\mathrm{Ca}^{2+}$-induced swelling, while in $100 \mu \mathrm{M} \mathrm{MC}$-treated samples a transient mild shrinkage was observed immediately after addition of $\mathrm{Ca}^{2+}$. Data are presented as means \pm S.E.M. $(n=3)$. (B) Immunoblotting demonstrated a strong release of cytochrome $\mathrm{c}$ of RLM into the medium by $\mathrm{Ca}^{2+}$, which was reduced by MC or was completely blocked by CsA. MC $(100 \mu \mathrm{M})$ alone showed a similar release of cytochrome $\mathrm{c}$ as it did in combination with $\mathrm{Ca}^{2+}$. A control without $\mathrm{Ca}^{2+}$ and without MC did not show any cytochrome c release. 
Fig. 5.

$M C$ is a powerful free radical scavenger. (A) Fluorimetric analysis of oxidative stress induced by application of $100 \mu \mathrm{M} \mathrm{H}_{2} \mathrm{O}_{2}$ in primary cortical cultures (13 DIV). $\mathrm{H}_{2}$ DFFDA preloaded cells $(100 \mu \mathrm{M}, 1 \mathrm{~h})$ showed a strong increase in DFF-fluorescence upon exposure to $\mathrm{H}_{2} \mathrm{O}_{2}$. Pre-treatment with $\mathrm{MC}(100 \mu \mathrm{M})$ almost abolished the increase of the fluorescence signal. (B) MC scavenged the model radical DPPH at a comparable rate as did L-ascorbic acid. DPPH spectrophotometric assay is based on the quenching effect of radical scavengers on the absorbance of DPPH. 


\section{(A)}
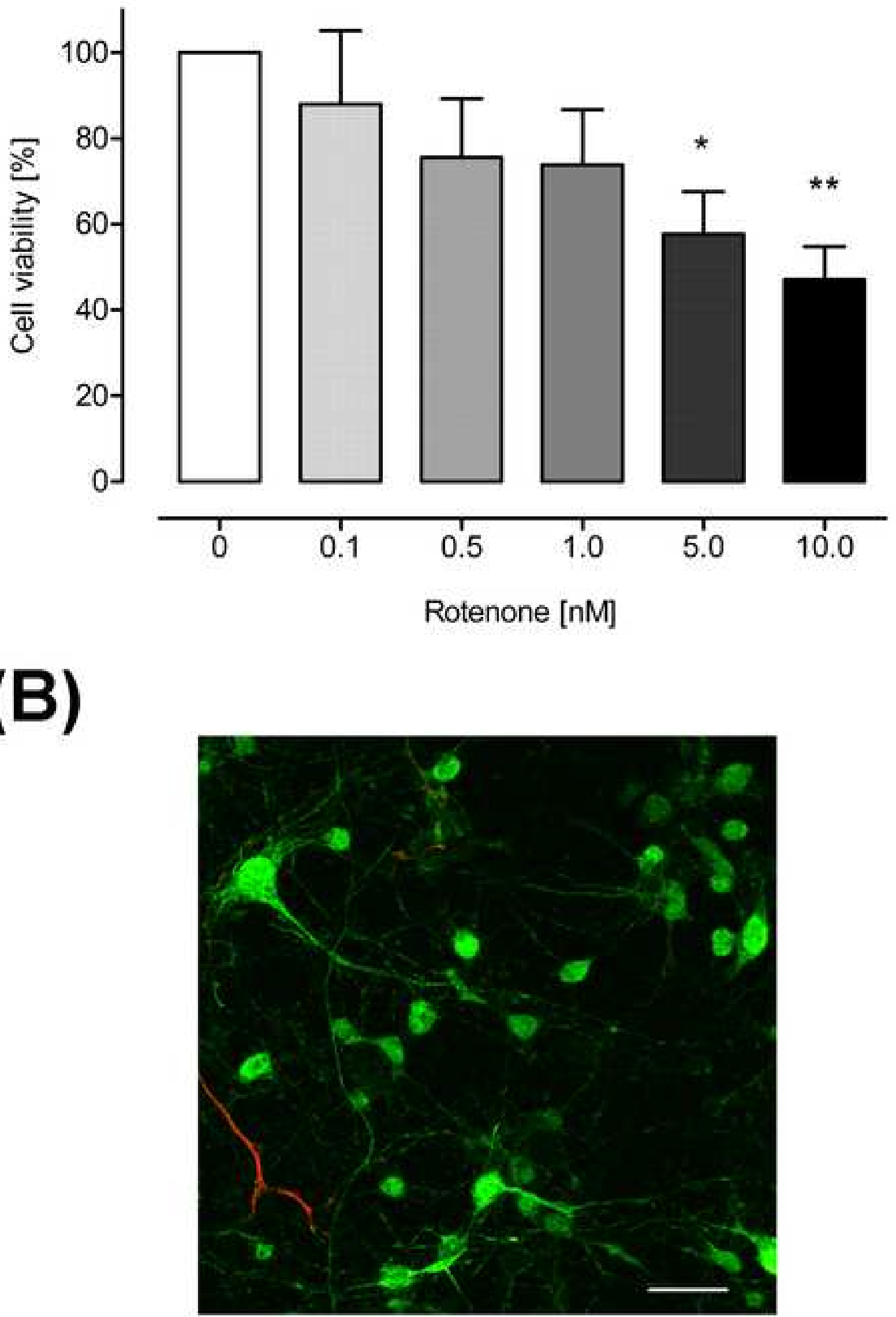
(A)

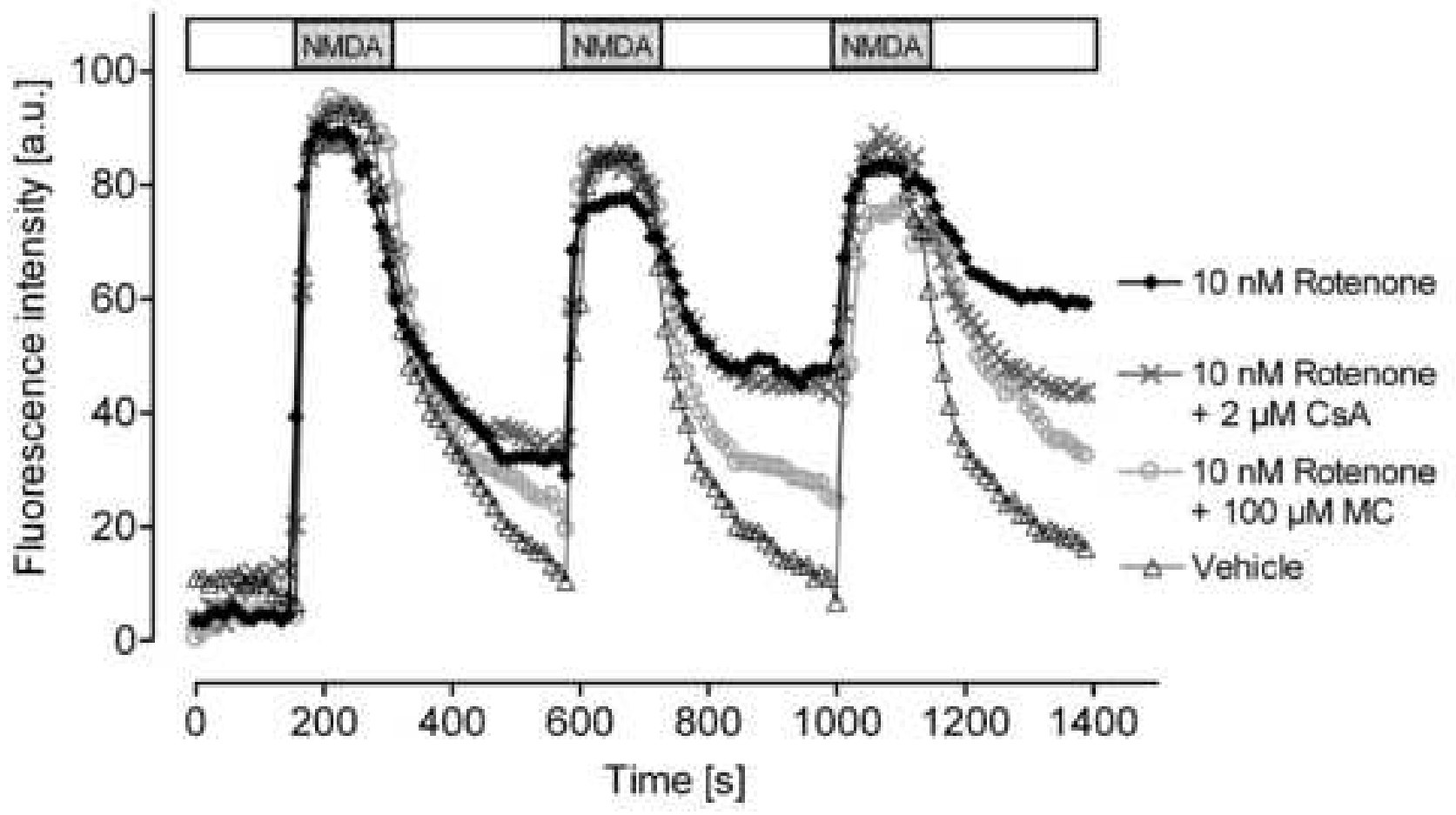

(B)

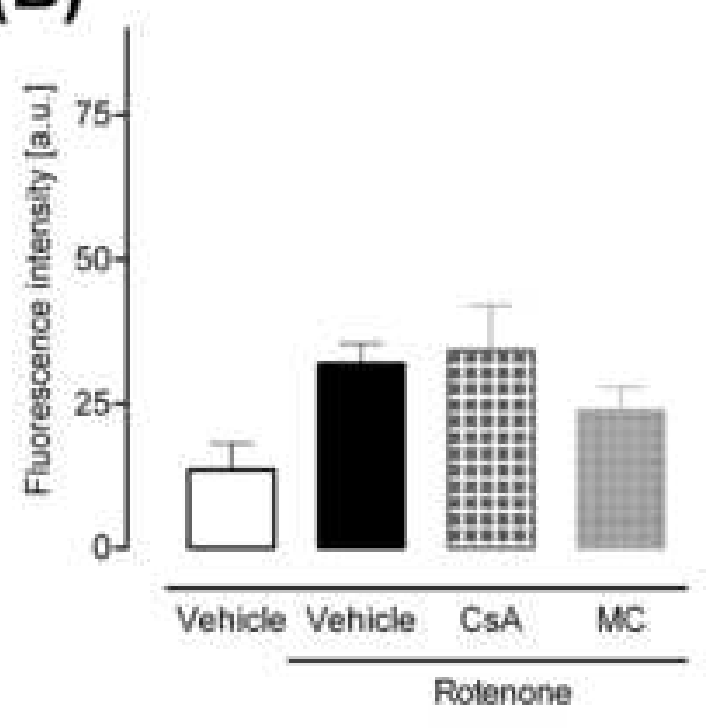

(C)

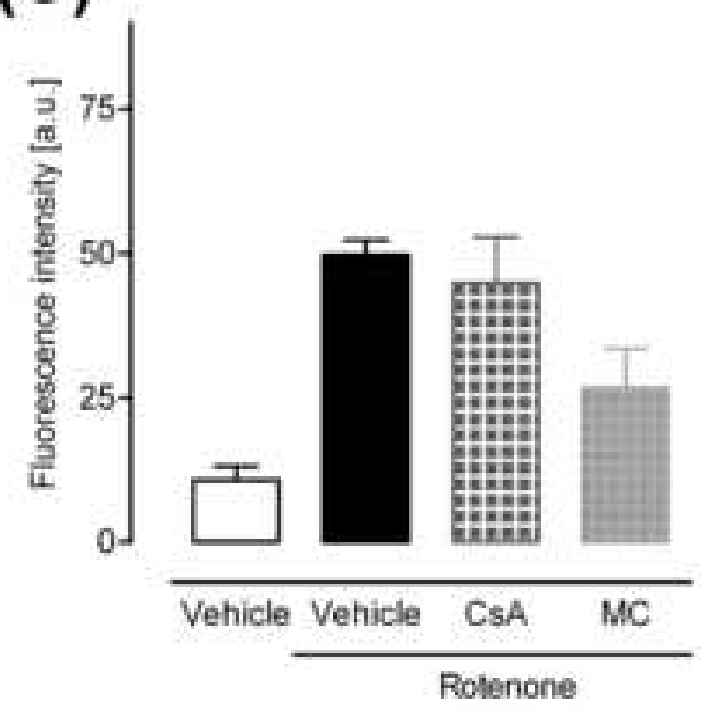

(D)

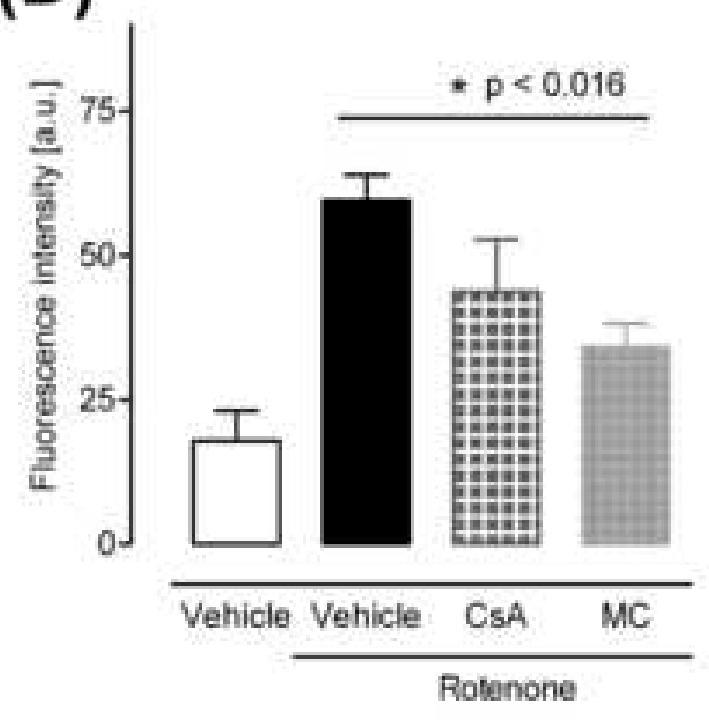

rage 30 or 33 
(A)

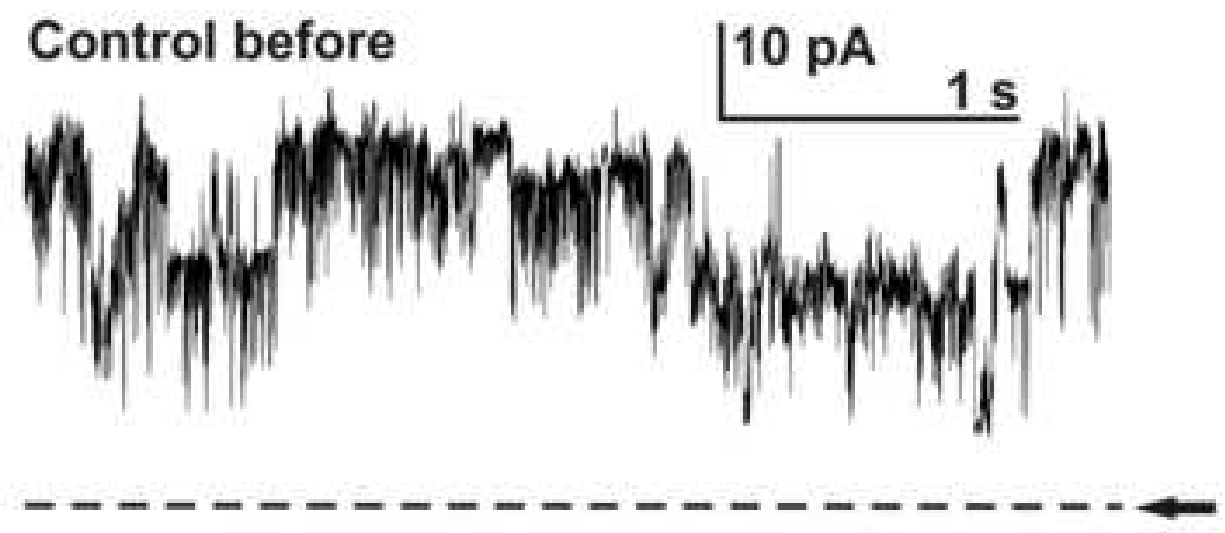

$10 \mu \mathrm{M}$ MC (403 s after)

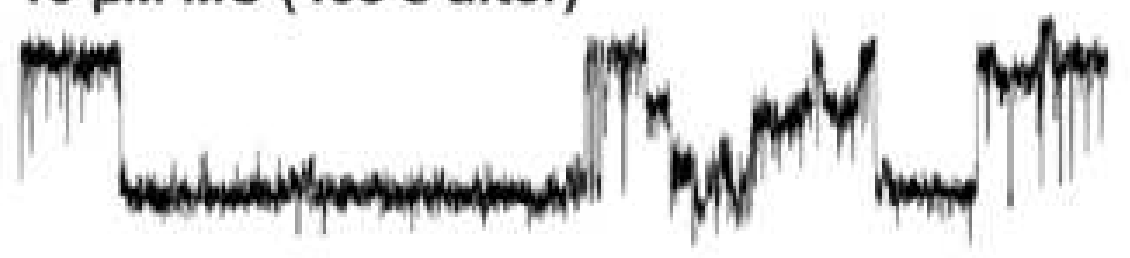

Control (317 s after MC)

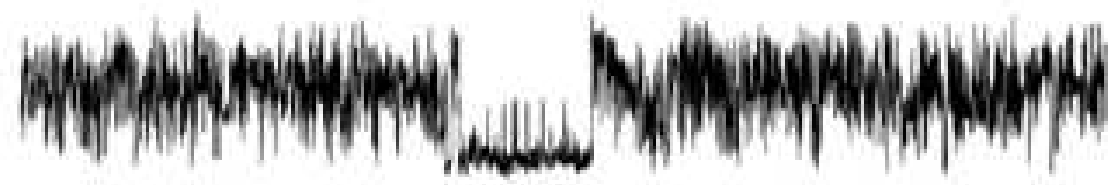

B)

(B)

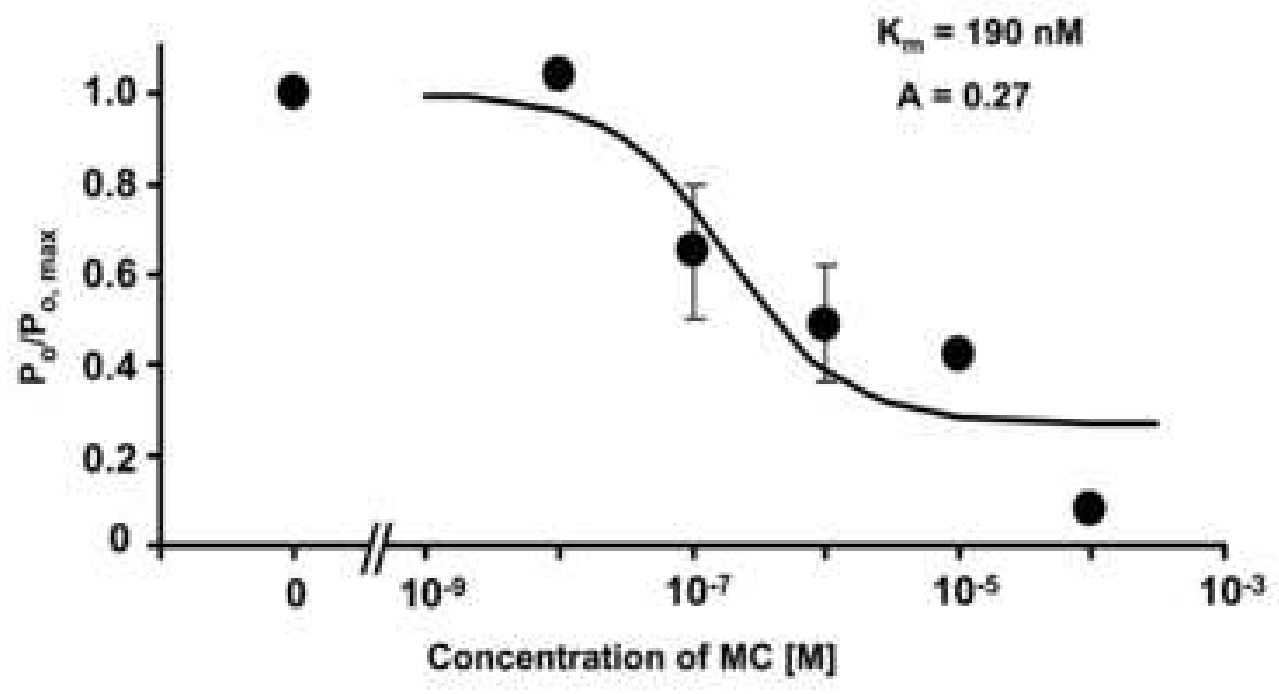




\section{(A)}

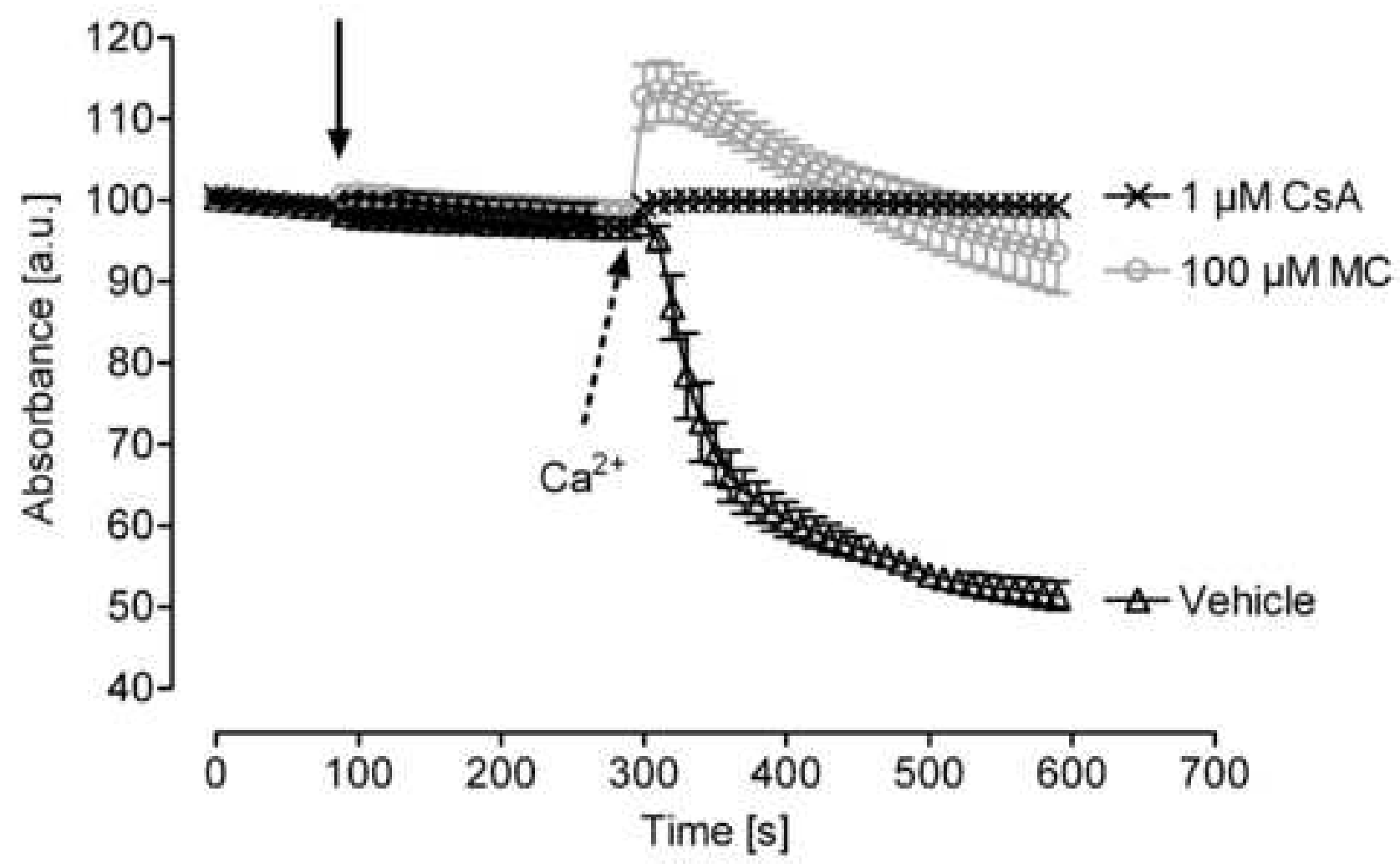

(B)

Cytochrome c

$\begin{array}{rlllll}\mathrm{Ca}[100 \mu \mathrm{M}] & - & + & + & - & + \\ \mathrm{MC}[100 \mu \mathrm{M}] & + & - & - & - & + \\ \mathrm{CsA}[1 \mu \mathrm{M}] & - & + & - & - & -\end{array}$




\section{(A)}
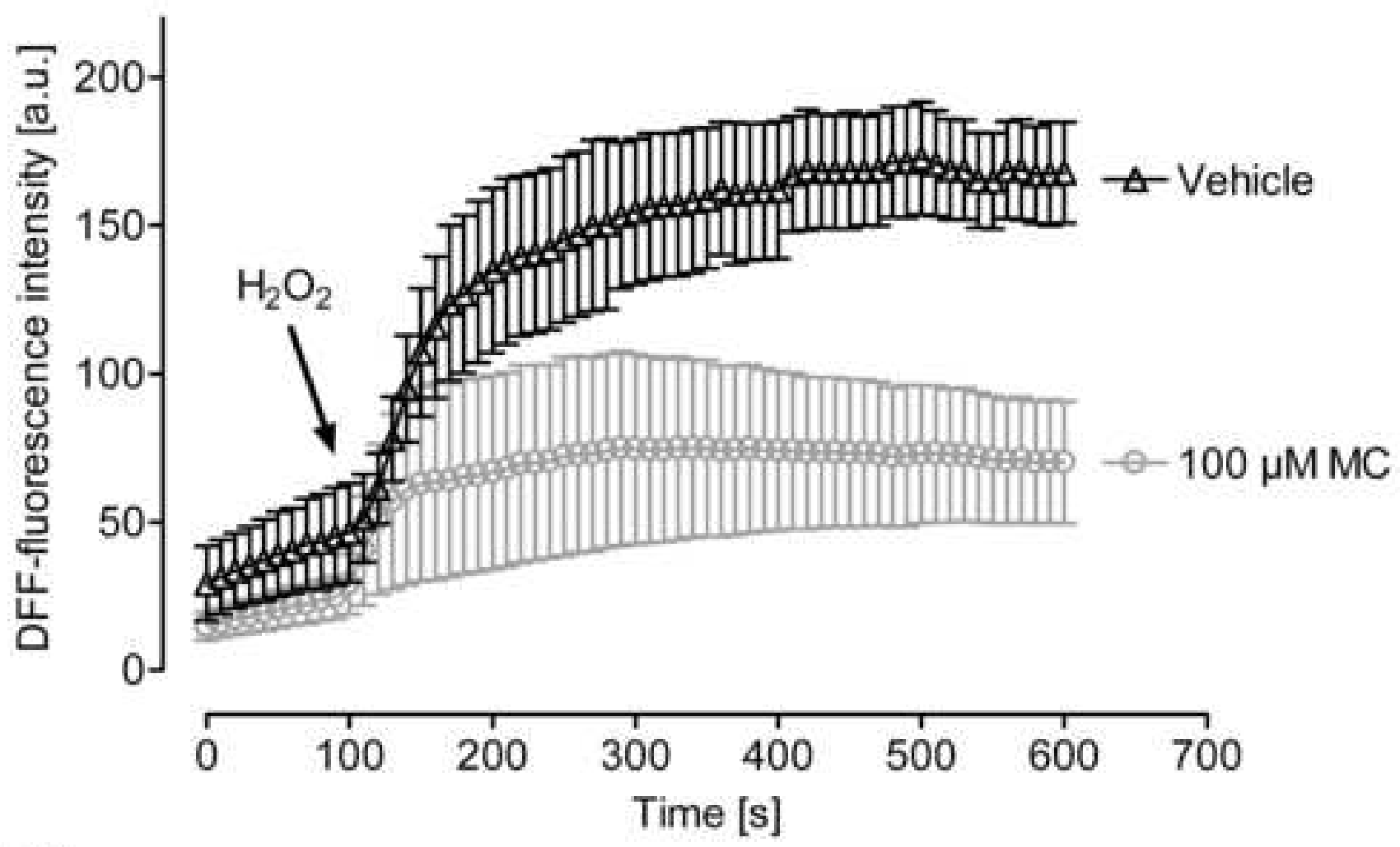

\section{(B)}

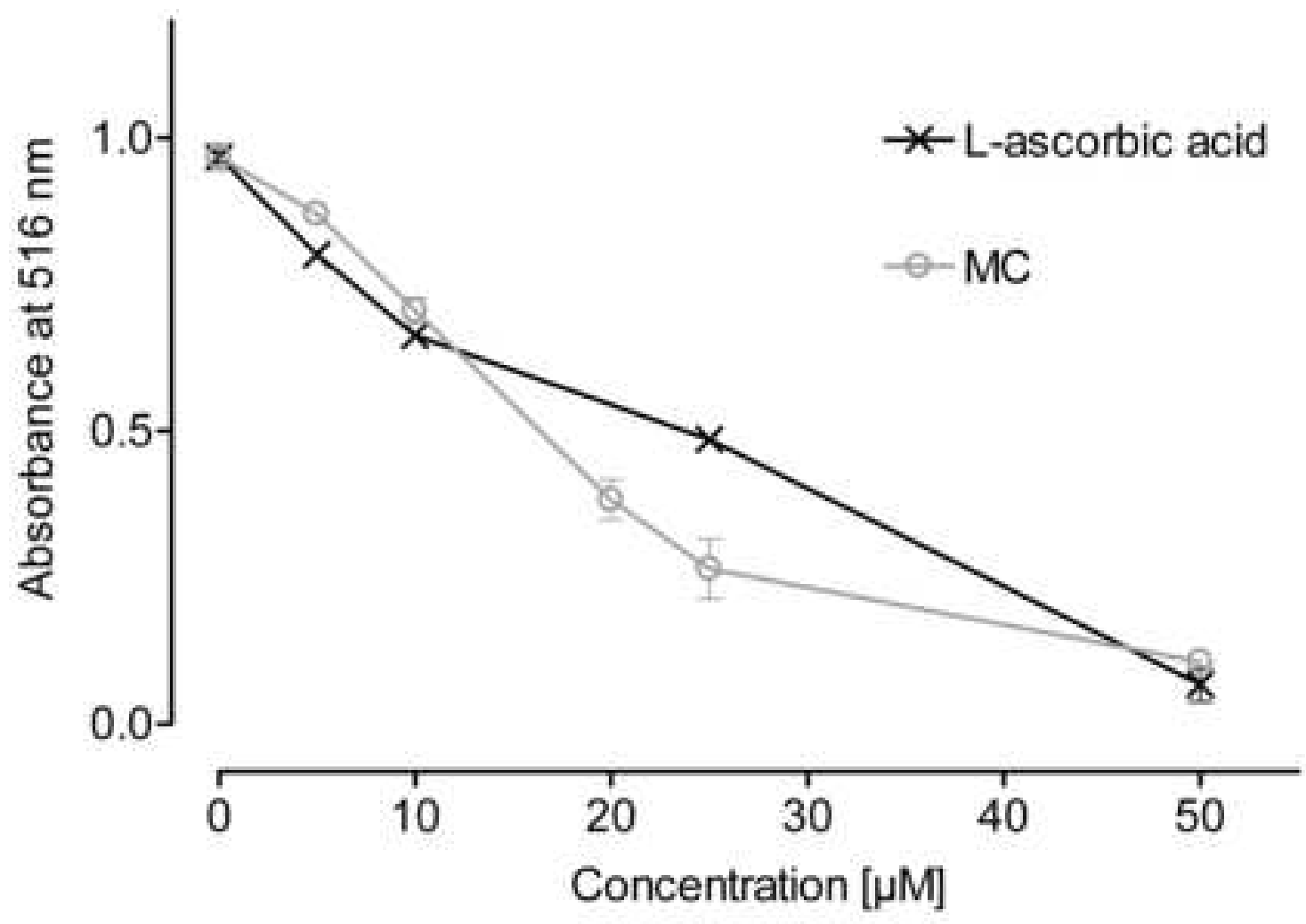

